of the unborn patient is the phrase used here to describe the introduction of treatment primarily directed at the fetus.

Early in the book the author states: "it is a key goal of this book to reframe fetal surgery as a women's health issue and to re-situate fetal personhood within the specific relationships in and by which it is produced". This perspective results in questioning much of the practice of fetal surgery, but whether this perspective is shared by expectant mothers is debatable.

The book documents the period from the start of intrauterine transfusions for Rhesus disease in 1963 through to the present, describing new developments in intrauterine surgery and other therapies given to the mother but designed to benefit the fetus in utero.

Describing in utero procedures, the author uses powerful language. Examples include: "the new practice fascinates and horrifies because it transgresses a number of medical and cultural boundaries"... . "breaches the womb in new and unsettling ways"... "makes us rethink some of our most cherished assumptions about life and the natural body"..."inspiring wonder and concern about our capacity to alter human destiny"... . "This book offers a critical social and cultural analysis of this nascent yet significant innovation in biomedicine" ..."foetal surgery is not by any means 'old stuff' especially in terms of its social and political consequences. It is medicine without boundaries, cowboy surgery on what is considered, at least for now, the final frontier."

The introduction of intrauterine transfusion in the early 1960 s was the first direct intervention aimed at the fetus, and the social and ethical issues are discussed. From this beginning, the number of intrauterine interventions that can be carried out has markedly increased, and in specialist centres operations may be performed on the fetus which is then returned to the womb. Inevitably, such procedures have a profound effect on the mother, when the direct benefit (if achieved) is to the fetus. However, most mothers would probably want such surgery to be undertaken.

The author provides an interesting and partisan review of the development of intrauterine interventions to aid the fetus, and draws attention to new ethical situations. These will need thoughtful analysis and debate in the years to come.

RICHARD WEST
Postgraduate Medical Dean, University of Bristol and General Secretary, Institute of Medical Ethics

\section{Buddhism and Abortion}

\section{Edited by Damien Keown, London, Macmillan, 1998, 222 pages, $£ 45$.}

This interdisciplinary collection of nine essays is a welcome and pioneering attempt to explore the abortion question from a number of Buddhist ethical and cultural perspectives. The book is divided into three parts. Parts one and two are area studies focused, respectively, on Thailand and Japan/ Korea. Part three is concerned with textual and normative issues.

The first chapter, by Robert Florida, provides a very useful introduction both to some basic Buddhist ethical principles, including the traditional prohibition on taking life, and to the current legal situation in Thailand, a Buddhist country with an abortion rate $50 \%$ higher than the US figure for the equivalent number of citizens. Cleo Odzer's succeeding chapter on Thai prostitutes, however, surprisingly reveals that while married women in Thailand regularly seek abortions, prostitutes do not. Pinit Ratanakul's chapter adds further information on the Thai context (including the increasing number of abortions of HIV positive fetuses), advocating a Thai "middle way" which acknowledges that sometimes abortion may be the lesser evil.

Part two includes two essays on the Japanese practice of mizuko kuyō, a Buddhist memorial service for aborted children. The first of these is an excerpt from William LaFleur's acclaimed 1992 book, Liquid Life, commending this Japanese response as one from which the West might learn. LaFleur suggests it is an interesting exemplar of the way in which Japanese "societal pragmatism" has achieved a consensus on abortion, forefronting the need for a solution without tearing the social fabric apart. The second essay, by Elizabeth Harrison, presents some of her research on lay participants' perceptions of the ritual and the way in which it fulfils a number of important social and psychological functions for Japanese women. In the third essay in this section Frank Tedesco provides a good deal of new information about the situation in Korea. As in Japan, the abortion rate in Korea is very his (partly driven there by son prefe ence). Moreover the rate among $K^{\infty}$ rean Buddhists is as high or higher than that of the rest of the population However, only rather recently hase Korean Buddhists begun to express concern for aborted fetuses and de mand memorial services for therf though of a distinctively Korean for

Part three begins with a review James McDermott of the ancient Pali textual sources on abortion, which regard it (especially for monastics) as serious breach of the Buddhist precent against taking life. James Hughes succeeding essay, however, sugges? that modern Western Buddhists do not need to follow these ancient texts slavishly. Instead Hughes favours $=$ Buddhist blend of utilitarian and virtue ethics, a "paradoxical unity compassion and wisdom", whis would allow abortion where the inter tion is compassionate and the act achieves the best outcome for all cof cerned.

The concluding essay by Damien Keown takes a more conservative line. Keown is sceptical of claims that Bu遮 dhism can offer a "middle way" abortion that steers a course betwee "pro-choice" and "pro-life" extremes. To this end he helps himself to th dubious assumption that any suct proposed Buddhist middle way musf be "distinctly or uniquely Buddhis? (page 202) before going on to make some conceptual heavy weather what the phrase "middle way" migh mean here (surely just a position that gives full moral weight to both the value of choice and the value of life Keown's central objection, however, is that the Pali textual tradition, particur larly its monastic code, unequivocal commits Buddhism to an exception. less pro-life position (his evidence for the textual claim is not presented here, but in his 1995 book, Buddhism ands Bioethics). Hence the only viable Budv dhist middle way on the issue is onf between the extremes of vitalism (the doctrine that life is an absolute value to be preserved at all costs) and "quap ity of life" utilitarianism. It is noteworthy how far Keown's fundamentaliș understanding of the authentic BuCP dhist position on abortion is from th\& of so many modern Asians and Westerners who count themselves Buddhists, including some of the other contributors to this volume.

Although all of the essays included in the volume are interesting and informative, there are obvious lactu nae. Indeed the editor himself disarm- 
ingly admits some of these (page 8): nothing on Tibet, nor on the Theravādin tradition in Sri Lanka or Burma, nor on Cambodia, Vietnam or China, nor on feminism. However, his defence of these shortcomings is weak: namely, that these just reflect the lack of research to date into these areas. In fact there already exists published work on Tibetan perspectives that could have been reprinted, and further work on all of these areas presumably could have been commissioned. Furthermore, as Keown does not specifically acknowledge, the volume is also weak on philosophy. Obviously, there already exists in the West a very large body of rigorous philosophical discussion on the issue of abortion, critically examining the rationality of the moral and non-moral judgments that supposedly justify various stands on the matter. It is regrettable that this volume includes no sustained attempt to engage with Buddhist views on abortion from that disciplinary perspective.

It is also regrettable that a book as expensive as this one should include a number of typographical lapses, the most serious of which is the omission (on pages 119-120) of what I estimate to be a full page of notes to Harrison's essay.

Notwithstanding these limitations, however, this is an interesting and worthwhile book that breaks quite a bit of new ground (particularly on the descriptive side). As such, it represents an initiative in cross-cultural bioethics that very much deserves to be built upon.

ROY W PERRETT

School of History, Philosophy E Politics, Massey University

\section{Alternative Medicine and Ethics}

\author{
Edited by James $M$ Humber and \\ Robert F Almeder, Humana Press, \\ 1998,220 pages, $\$ 44.50 \mathrm{hb}$.
}

Despite the growing popularity of complementary and alternative (CAM) therapies both in the UK and the US, surprisingly little has been written about the ethical dimensions of the holistic CAM relationship. Such literature as there is often transposes the discourse of medical ethics to the CAM relationship mutatis mutandis, overlooking the substantial differences between the nature of the professional relationships. Arguably, the ethical concerns which affect the CAM relationship, which is essentially subjective, holistic and intuitive, are very different from those arising in an orthodox relationship which is, characteristically objective, symptombased and rational. When considering beneficence, for example, "healing" in the CAM sense takes on a much broader definition, referring to improvements which can occur on an emotional, psychological or spiritual level, without the patient necessarily being cured of specific disease symptoms.

Alternative Medicine and Ethics is certainly a useful starting point for debate. This multi-authored text includes thought-provoking chapters on orthodox practitioners as gatekeepers to CAM, insurance coverage for CAM, and ethical and legal dilemmas surrounding prayer as a method of alternative healing for children. Although written from an American perspective, the issues are extremely pertinent in the UK, where a major initiative, established by $\mathrm{HRH}$ The Prince of Wales, is currently looking at the whole area of integration of CAM and orthodox medicine.

Ever since the passing of the Quacks' Charter of 1542, the status of complementary medicine has been the subject of sustained political debate. Indeed, what has linked over 150 diverse therapeutic approaches in the past is their exclusion from what has been taught in orthodox medical schools, and the unwillingness of insurers to pay for them. Even the choice of nomenclature - "complementary" or "alternative" - represents the divide as to whether therapists see themselves as supplementary to orthodox medicine or as a genuine alternative, and it is interesting that this book chooses the latter term, whereas in the UK the preferred term is "complementary", and increasingly, we read of "integrated medicine".

Those alternative practitioners who regard the medical profession's antipathy towards CAM as having more to do with medical territorialism and less to do with the best interests of patients will find no comfort in the book's forthright opening chapter: "Alternative medicine: more hype than hope". In fact, this tirade by Stephen Barrett is almost comical in its one-sidedness. As though side effects and iatrogenic illness did not exist, he writes: "With safe and effective medicines available, treatment with herbal products makes little sense". So much for promoting patient choice!
Weitzman, in his chapter on insurance coverage, by way of contrast, takes as his starting point the much quoted findings from a 1993 survey that nearly one in three of the population in the US used some form or other of CAM therapy, spending $\$ 13.7$ billion out of their own pockets for services not covered by health plans. Patel's chapter, "Understanding the integration of alternative modalities into an emerging healthcare model in the United States", provides a thoughtful analysis of what integration might mean in practice and what might be lost by forcing CAM therapies, which traditionally offer a compassionate, caring and humane approach, into the environs of orthodox medicine. In doing so, he poses critical questions about how the Cartesian/ Newtonian biomedical model can be reconciled with the mind-body philosophies underpinning CAM therapies.

The chapters on health plans as gatekeepers and insurance coverage for alternative medicine may need some translation for a UK readership, but the central issues are the same on both sides of the Atlantic, namely the reluctance to integrate or fund CAM therapies which are not substantiated by scientific research at a time when orthodox medicine is being increasingly driven in an evidence-based direction. Again, although drawing entirely on US case law, Neeley's chapter on "Prayer as a method of alternative healing" raises fundamental issues about parental rights of decision making, and whether it can ever be right to abandon orthodox medicine in favour of CAM approaches for one's children, a question which is yet to reach the British courts.

This is a fascinating book which deserves a wide readership. As well as its obvious interest to complementary and alternative therapists, it raises important general issues of health care ethics and law. It should certainly be read by general practitioner and health authority purchasers who may be interested in purchasing CAM therapies, and will, it is to be hoped, be taken up by the growing number of medical schools offering special study modules in this subject.

\section{JULIE STONE}

Senior Lecturer in Health Care Ethics and Law, University of Greenwich School of Health 